\title{
Laboratory Safety System using IOT
}

${ }^{1}$ S V Priya, ${ }^{2}$ G. Indhumathi, ${ }^{3}$ S. Vignesh, ${ }^{4} \mathrm{U}$ Swamyvel Chandar, ${ }^{5} \mathrm{~K}$. Dinesh

${ }_{1,2,3,4,5}$ Department of ECE

$1,2,3,4,5$ Loyola Institute of Technology, Chennai, India

1srisvpriya@gmail.com. ${ }^{2}$ Indhushine@gmail.com, ${ }^{3}$ vigneshvickey155@gmail.com, ${ }^{4}$ samvelchandarpaul51@gmail.com,

5 dineshkd03.dk@gmail.com

\section{ABSTRACT}

Internet of Things (IoT) conceptualizes the idea of remotely connecting and monitoring real world objects (things) through the Internet. This concept can be aptly incorporated to make laboratories smarter, safer and automated. This IoT project focuses on building a smart lab safety system which sends alerts to the owner by using Internet in case of any danger and raises an alarm optionally.A safety system needs to be designed to ensure at most safety in the laboratories.

Keywords:

Automation, Chemical, Hazards, IOT, RFID, Safety.

Article Received: 18 October 2020, Revised: 3 November 2020, Accepted: 24 December 2020

\section{Introduction}

Automation not only refers to reducing human efforts but also energy efficiency and time saving. The main objective of project is to control the lab even from remote locations and incaseof emergency.

We are also working on energy saving. The critical parameters are monitored and incase of emergency control action can be taken. The system is secured, userfriendly, reliable, flexible and affordable.

\section{Objective:}

- To maintain safety in laboratories

- To alert in case of emergency

- To conserve energy comsumption as much as possible

- To transfer data to incharge using IOT

\section{Areas of lab safety}

- Chemical safety

- Bio safety

- Gas safety

- Fume hood safety

- Electrical safety

- Water safety

- Radiation safety
- Laser safety

- Fire safety

\section{Related work}

Fire Sensor

In laboratory, fire hazard needs emergency response with firefighting equipment. But during summer months with high heat index, in case of any major fire, combating fire is a big challenge. Temperature fluctuations may be caused by changes in weather, location or layout, cooling equipment, air circulation and many other factors.

In case of any major gas leaks from catastrophic failure of the equipment or pipelines, which may leads to disaster. Electrical shortcircuits can also lead to fire.

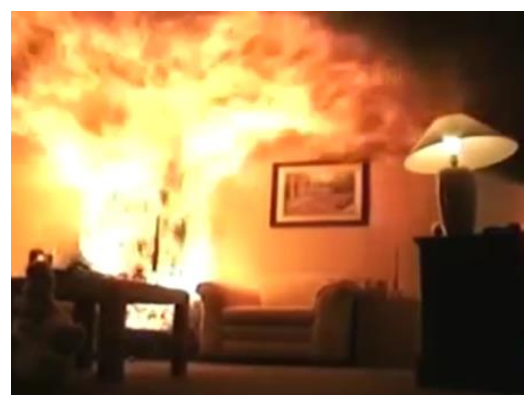

Fig: 1 Fire accident

\section{Gas Leak Sensor}


Hazardous gases can evolve from indoor and outdoor sources including gaseous contaminants, particulates, fumes, odour complaints, amongst others. In the chemical laboratories, Several poisonous gases are being used. Chemicals like H2S, Phenol, Hydrofluoric acid and many other gases are harmful to humans. If inhaled or come in contact with these for a longer period, eyes irritation, skin irritation and respiratory problems can occur.

Poisonous gases should be monitored and indicated to the in charge and if necessary an audible alarm to be generated.

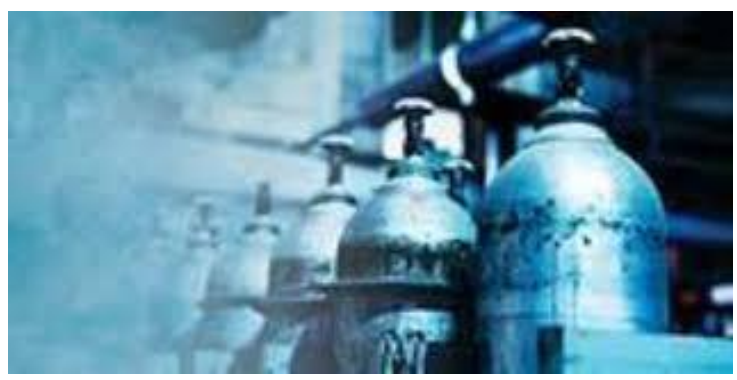

Fig: 2Gas leak hazard

\section{Light Sensor}

The controlling of room lights and fans are typically operated manually. The manual operation is risky and causes power wastage due to the negligence of humans and also some unusual conditions of elecrtonic components.

An human detector is placed in the room so that when there is no human movement for a predefined time, the lighting system will be automatically switched off. By this idea, energy is conserved

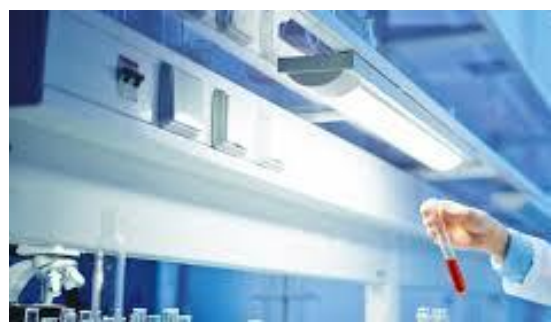

Fig: 3 Room lighting system

\section{Proposed model}

- If the values crosses a set value alert the human by generating alarm.
- The lab is to be monitored continually for any abnormality. There are three parameters that plays key role in safety.

If the measurand level increases above a limit, it generates an audible alarm. If the level goes above danger, then mitigation will be initiated.The real time status can be monitored remotely using IOT.

IOT messages received by users will enable the users to take immediate action against the gas leak or fire accident.

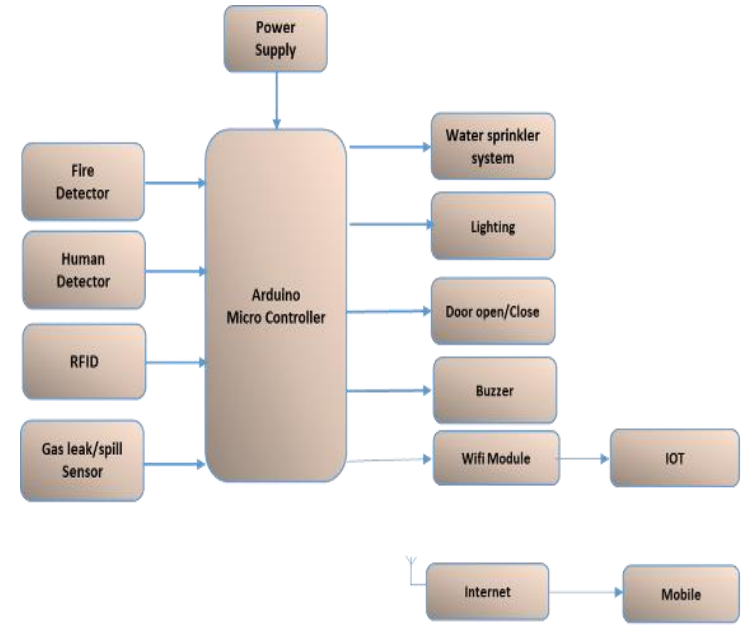

Fig: 4 Block Digram

Hardware Requirement:

- Arduino Uno MicroController

- Gas leak sensor

- Fire Detector IR

- Human Detector PIR

- RFID Reader

- Buzzer

- Door open / Close

- Lighting control

- Sprinkler pump

- WiFi ESP8266

\section{Software Requirement:}

- Arduino microcontroller programming Software

- Computer USB interface Software

- Microsoft office software

Theory

\section{Hardware Description:}




\section{Micro Controller:}

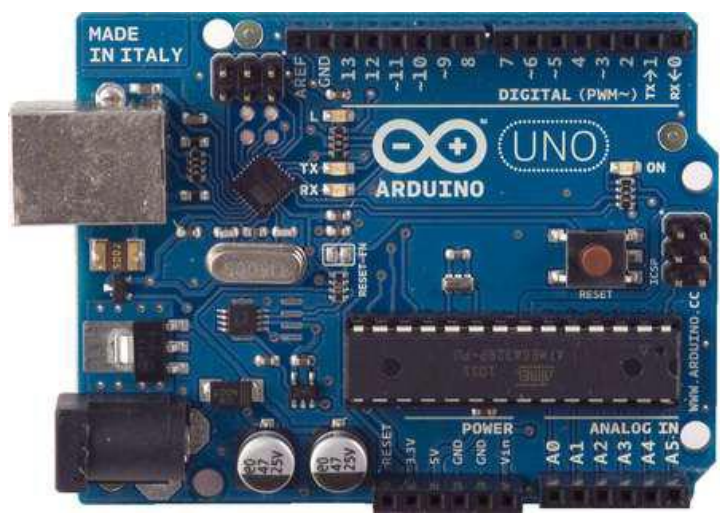

Fig: 5 Arduino Microcontroller

Arduino is an open source architecture that uses Atmega microcontroller. The Arduino platform provides an integrated development environment (IDE) based on the Processing project, which includes support for $\mathrm{C}, \mathrm{C}++$ and Java programming languages. Arduino has different types based on number of pins such as Arduino Uno and Arduino Mega and Arduino Nano.

14 Digital IO pins (pins 0-13) : There are 14 digital pins which can be defined as input or output during programming in the uno IDE.

6 Analog In pins (pins 0-5) : These 6 analog pins read analog values(voltage) from sensors and convert them into a number between 0 and 1023 .

6 Analogue Out pins (pins 3, 5, 6, 9, 10, and 11)

: These pins are analog output pins, alos called as PWM pins. Output devices whose speed needs to be controlled can be programmed to these pins.

\section{H2S Sensor:}

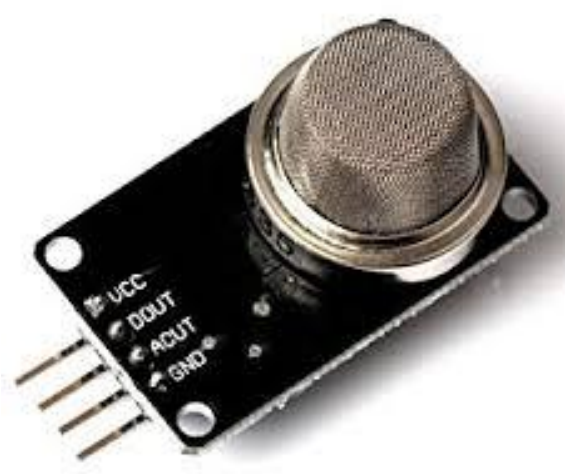

Fig:6MQ-136 H2S SENSOR
MQ-136 gas sensor is sensitive to $\mathrm{H} 2 \mathrm{~S}$ and other harmful gases in the atmosphere. The conductivity of the gas sensor changes along with the concentration of the polluting gas in the environment.

MQ-136 performs a good detection to smoke and other harmful gas, especially sensitive to ammonia, sulfides and benzene steam. This sensor's sensitivity and low cost makes it sutiable for many applications.

\section{Flame sensor:}

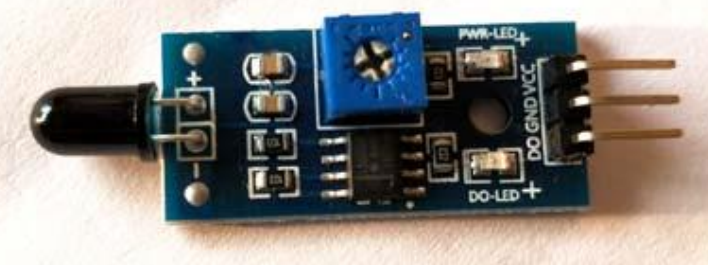

Fig:7 Flame Detector

A flame detector is used to detect and respond to the presence of a flame or fire. The sensor sends a signal when the flame or fire is detected and the necessary control action can be made using the controller program.

Flame sensor module working voltage is between $3.3 \mathrm{v}$ and $5 \mathrm{v}$ DC. The sensor is digital, that is this sensor gives out digital signal (1or 0). Logic high at output means flame is present and logic low indicates flame is absent.

\section{Human Detector:}

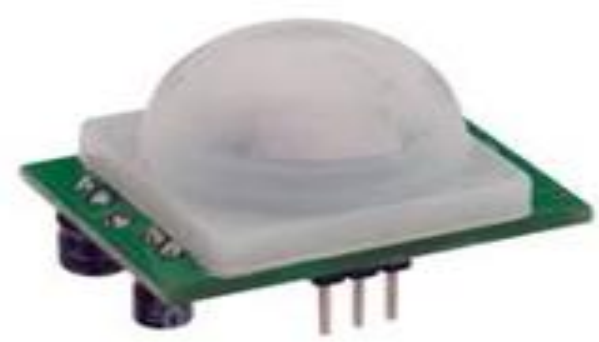

Fig:8 PIR Sensor 
The PIR (Passive Infra-Red) Sensor is a pyroelectric device that detects motion by measuring changes in the infrared levels emitted by surrounding objects.

When an object, such as a human, passes in front of the sensor, there is a temperature change and the sensor detects and sends a signal. A High signal is send at the output pin of the sensor. This indicates the presence of human near the sensitivity range of the sensor. The range of sensitivity of the sensor can be adjusted using the potentiometer.

\section{RFID:}

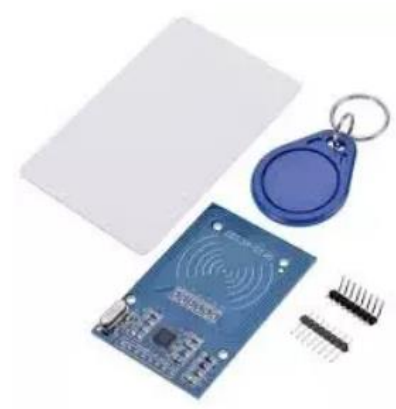

Fig:9 RFID

RFID, or Radio Frequency Identification, is a system for transferring data over short distances.One of the two devices needs to be powered and the other is a passive device.

The downside is that the reader and the information holder (ie credit card) must be very close, and can only hold small amounts of data.One of the application of RFID (RadioFrequency Identification) is to detect if the employee goes into or out of plant and there are many other such applications using RFID.

\section{Liquid Pump:}

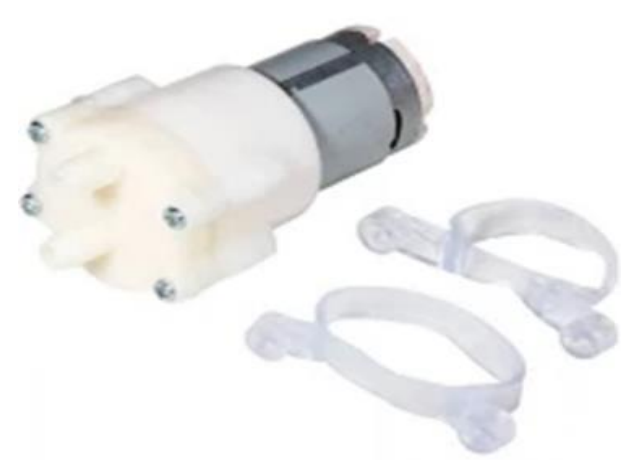

Fig: 10 Water Pump
A diaphragm pump (also known as a Membrane pump) is a positive displacement pump that uses a combination of the reciprocating action of a rubber, thermoplastic diaphragm and suitable valves on either side of thediaphragm to pump a fluid.

Diaphragm pumps works in the principle in which the diaphragm is sealed with one side in the fluid to be pumped, and the other in air or hydraulic fluid and the diaphragm is flexed thus causing the volume of the pump chamber to increase and decrease therefore pumping liquid.

\section{Wifi Module:}

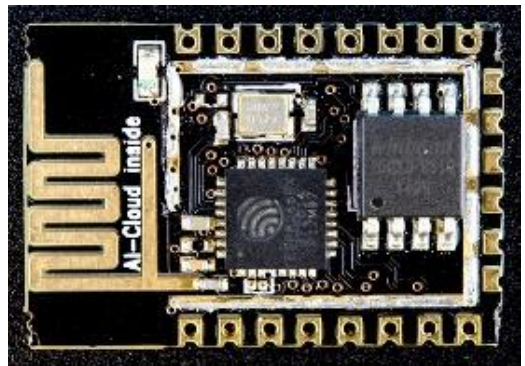

Fig:11 Esp-12e Wifi Module

The ESP8266 has become a goto for development of inexpensive IoT applications. WiFi chips have been available for around a decade, you may be wondering what makes the ESP8266 special.

This chip is widely used for all types of Wifi applications and projects. This chip supply voltage is $3.3 \mathrm{~V}$ dc and can be programmed using IO pins in it. Many development boards have also been developed using this chip.

\section{IOT}

The Internet of Things (IoT) is used widely in several ways. The need for IOT is increasing day by day as more and more organizations and industries are focusing on IOT revolution.The number of connected devices on the IoT network is tremendously increasing.

Blynk is a Platform with iOS and Android apps to control Arduino, Raspberry Pi and many other devices over the Internet.In Blynk you can 
build a graphic interface for your project easily and start working right away.

Blynk supports hardware of your choice. Whether Arduino or Raspberry, Ethernet or new ESP8266 chip can be connected over internet and Internet of things application can be established.

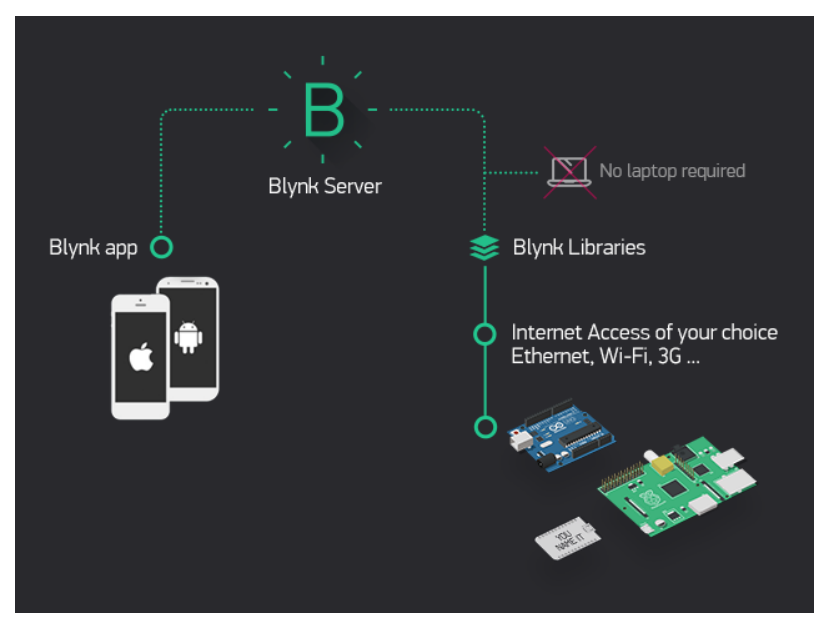

Fig:12 Blynk process flow

Blynk was designed for the Internet of Things. It can control hardware remotely, it can display sensor data, it can store data, vizualize it and do many other things.

There are three major components in the platform: Blynk App - It allows you to create interfaces for projects using various widgets provided.

Blynk Server-It is responsible for communications between the smartphone and hardware. It is open-source and could easily handle thousands of devices like Raspberry Pi and other devices.

Blynk Libraries-Used for all the popular hardware platforms. It enable communication with the server and processes the incoming and outcoming commands from the mobile.

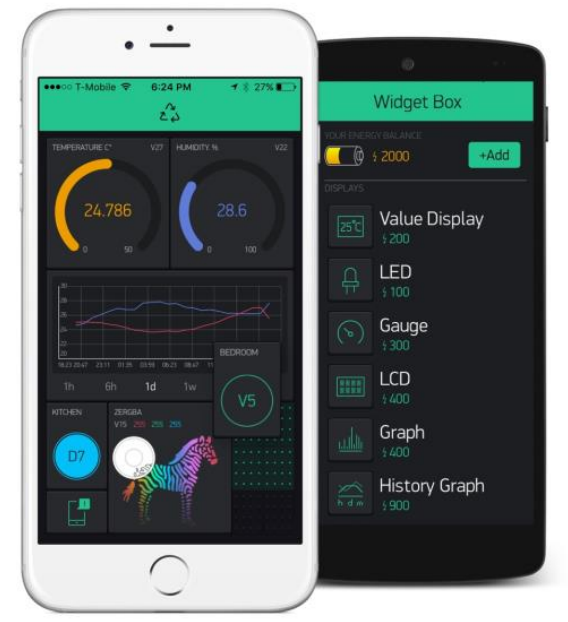

Fig:13 Blynk example

\section{The Control Scheme:}

- The sensors are connected to microcontroller. The micro controller reads the present value of all the sensors.

- The gas value is compared with alarm limit. If any of the value exceeds the alarm limit, then a buzzer is generated to alert the human.

- The human detector monitors an if there is no movement for a predefind time, then a bulb is switched off automatically.

- The fire detector monitors the presence of fire. If fire is detected, then a sprinkler water pump is switched on to put off the fire.

- All the parameters are transmitted to cloud through wifi transceiver. The intensity of light can be varied from IoT.

\section{Result}

- A working model to maintain safety for laboratory is designed.

- Abnormal parameters are sensed and alerted.

- Thus the safety for the labs are provided.

- Both human safety and material is being provided using our project. 


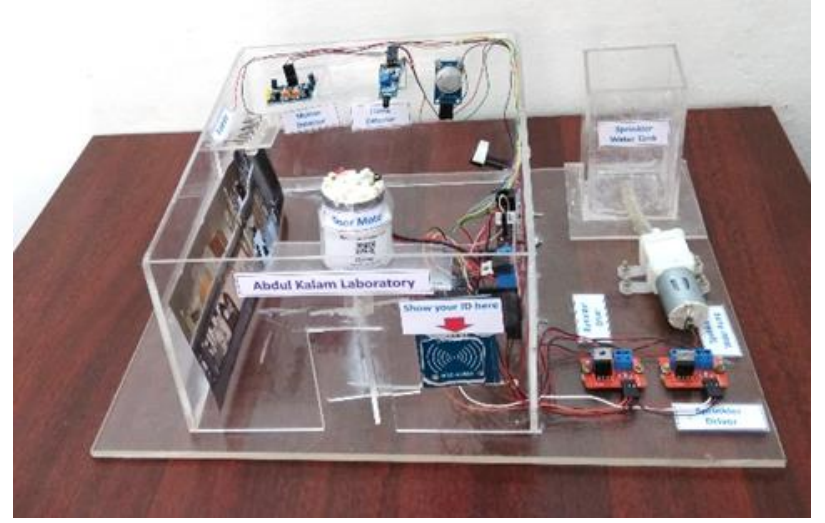

Fig: 14 Project Model

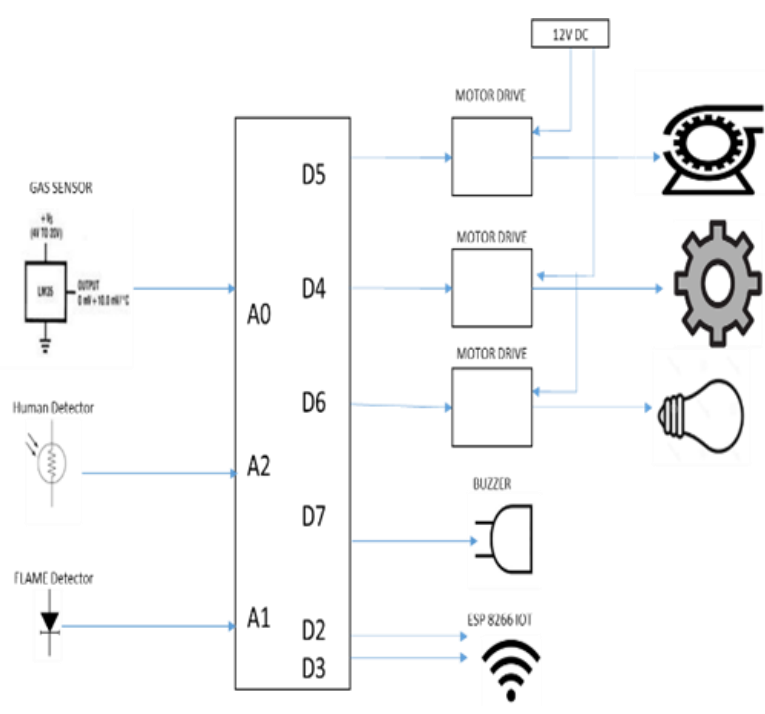

Fig: 15 Circuit Diagram

\section{Conclusion}

Safety.The electronic devices can be swtiched off from remote locations using mobile when danger is encountered. Alert can be created thus alerting people in the room to move out, saving human lives.

Security.Only authorised user can access the room. You can be alerted every time there is an abnormality, especially when you are not present.

Convenience. By usingsmart phone one can easily monitorthe lab parametersand control everything with just touch of a finger.

Saves Time.With automation in line one can make sure everything is order even from remote locations using mobile app.

Save Money. This low cost automation project can be applicable to all rooms for safety and by monitoring the necessary parameters, damage of electronic components can be minimised and energy can be saved.

\section{Acknowledgment}

We are personally indebted to a number of persons that a complete acknowledgement would be encyclopaedic. First of all, we would love to record our deep gratitude for our parents for permitting us to take up this course.

My sincere thanks and profound sense of gratitude goes to our respected Chairman, NAME for all his efforts and administration in educating us in this premiere institution. We take this opportunity to thank our Principal NAME, for his kind cooperation in completing this Project.

We would like to express our gratitude NAME Head of the Department of Electronics and Communication Engineering. for his guidance and advice all through our tenure. We convey our sincere thanks to our internal guide NAME for valuable suggestions throughout the duration of the project

\section{REFERENCES}

[1] Lamir Shkurti, Xhevahir Bajrami, Ercan Canhasi, Besim Limani, Samedin Krrabaj and Astrit Hulaj, "Development of Ambient Environmental Monitoring System Through Wireless Sensor Network Using NodeMCU and WSN Monitoring", 6th MEDITERRANEAN CONFERENCE ON EMBEDDED COMPUTING (MECO), JUNE 11-15 2017, BAR, MONTENEGRO.

[2] Vaishnavi S. Gunge and Pratibha S. Yalagi, "Smart Home Automation: A Literature Review", National Seminar on Recent Trends in Data Mining- RTDM 2016.

[3] Hayet Lamine and Hafedh Abid, "Remote control of domestic equipment from an Android application based on Raspberry Pi card", IEEE transaction 15th international conference on Sciences and Techniques of Automatic control \& computer engineering 
- STA'2014, Hammamet, Tunisia, December 21- 23, 2014.

[4] Gurek A., Gur C., Gurakin C., Akdeniz M., Metin S. K., Korkmaz I., (2013), “An Android Based Home Automation System", High Capacity Optical Networks and Enabling Technologies, IEEE 10th International Conference on, pp.121-125.

[5] Piyare R., Tazil M., (2011), "Bluetooth Based Home Automation System Using Cell Phone", Consumer Electronics, IEEE 15th International Symposium on, vol.45, no.3, pp.192-195.

[6] Tan K. K., Lee T.H., soh C. Y., (2002), "Internet Based Monitoring of Distribute Control System in Undergraduate Experiment), Education IEEE Transaction on , vol.45,no.2,pp.128-134.

[7] Sriskanthan N., Tan F., Karande A., (2002), "Bluetooth Based Home Automation", Microprocessors and Microsystems, Elsevier Science B.V. vol.26, no.6, pp.281-289.

[8] Yamazaki T., (2006), "Beyond The Smart Home", Hybrid Information Technology, IEEE International Conference on, vol.2, pp.350-355.

[9] Al-Ali A. R., Al-Rausan M., (2004), "Java Based Home Automation System", Consumer Electronics, IEEE Transactions on, vol.50, no.2,pp.498-504.

[10] Arduino CookBook, By Michael Margolis, O'Reilly Media, July 2014. 